\title{
Perioperative Clinical Interventions That Modify the Immune Response in Cancer Patients
}

\author{
María F. Ramírez ${ }^{1}$ Johannes M. Huitink ${ }^{2}$, Juan P. Cata ${ }^{{ }^{*}}$ \\ ${ }^{1}$ Department of Anaesthesiology and Perioperative Medicine, The University of Texas MD Anderson Cancer Centre, Houston, USA; \\ ${ }^{2}$ Department of Anaesthesiology, VU University Medical Centre, Amsterdam, The Netherlands. \\ Email: ${ }^{*}$ jcata@mdanderson.org
}

Received January $17^{\text {th }}, 2013$; revised April $1^{\text {st }}, 2013$; accepted April $15^{\text {th }}, 2013$

Copyright @ 2013 María F. Ramírez et al. This is an open access article distributed under the Creative Commons Attribution License, which permits unrestricted use, distribution, and reproduction in any medium, provided the original work is properly cited.

\begin{abstract}
The immune system plays a pivotal role against cancer. The development of a successful immune response involves the balance between the Th1 (antitumor) and Th2 (protumor) responses. Once this balance is lost, diseases such as cancer may become apparent. Surgical stress, volatile anaesthetics, opioids and blood transfusions are known to favour a Th2 response that manifests as immune suppression. During surgery the load of circulating malignant cancer cells is increased by tumour manipulation. These cancer cells can migrate and seed in distant tissues and form metastasis. Also, some cancer patients may present with micrometastasis that may become invasive if left untreated. Therefore, the perioperative period is a moment of immunological vulnerability in cancer patients. A better understanding of the factors that affect the Th1/Th2 balance may allow anaesthesiologists to identify patients at high risk for cancer recurrence. This review describes the perioperative interventions that can alter the Th1/Th2 balance, during the perioperative period of oncological surgery.
\end{abstract}

Keywords: Neoplasm; Surgery; Anaesthesia; Cytokines; Neoplasm Recurrence; Immune Response; Opioids; Volatile Anaesthetics

\section{Introduction}

The immune system plays a pivotal role in clearing new forming malignant cells and it does so by favouring antitumor mechanisms such as the production of cytokines. These cytokines have not only the ability of inducing cancer cell death directly but also by stimulating the function of cells such as natural killer cells and cytotoxic lymphocytes [1].

CD4 T helper cells are lymphocytes that strongly modulate the response of the immune system against cancer cells proliferation and tumour growth. They are classified into Th1 and Th2 cells based on their function and cytokine profile [2]. Th1 cells release IFN- $\gamma$, IL-2, and TNFa (Th1 cytokines); incontrast, Th2 cells secrete IL-4, IL-5, IL-10, and IL-13 cytokines (Th2 cytokines). Mosman et al. [3] established the Th1/Th2 balance paradigm to better understand the relevance of the Th1 and Th2 cytokines in different physiological or pathological disorders (Table 1). A shift towards Th1 polarization (Figure 1) is the expected response against cancer. For instance, IL-2,

${ }^{*}$ Corresponding author. the prototypical Th1 cytokine, has shown anticancer activity by augmenting cytolytic activity of NK cells, by inducing IFN- $\gamma$, and by activating macrophages [4]. In contrast, Th2 cytokines promote matrix metalloproteinase expression, invasiveness, and metastasis [5].

Cancer patients may suffer from significant immunosuppression that is characterized by a predominant Th2 state. This is the result of the cancer itself [6] malnutrition, chemotherapy, stress, concurrent diseases, medicationsand surgery [7]. The latter remains as one of the main therapeutic options for a large number of solid cancers but unfortunately, there are perioperative factors that alter the balance between the Th1 and Th2 cytokines favouring a predominant Th2 (protumor) state. Those factors include surgery-induced stress, anaesthetics, analgesics and blood transfusion. Thus, it is important to highlight the concept perioperative immunosuppression because it is the time in which dormant [8] and occult tumours [9] and circulating tumour cells [10] have increased possibilities of seed and growing even after the primary tumour has been resected [11]. It has been hypothesized that avoiding some or all those factors would 
Table 1. Th1 and Th2 cytokines and their main functions.

\begin{tabular}{|c|c|c|c|}
\hline \multicolumn{2}{|r|}{ Th1 cytokines } & \multicolumn{2}{|r|}{ Th2 cytokines } \\
\hline IFN- $\gamma$ & $\begin{array}{l}\text { Enhances the microbicidal function of macrophages. } \\
\text { Promotes the differentiation of naive helper T cells into Th1 cells. } \\
\text { Activates polymorphonuclear leukocytes, cytotoxic T cells, and } \\
\text { NK cells. }\end{array}$ & IL-4 & $\begin{array}{l}\text { Regulates antibody production, haematopoiesis, and } \\
\text { inflammation. } \\
\text { Promotes the differentiation of naive helper T cells into Th2 cells. } \\
\text { Decreases the production of Th1 cells. }\end{array}$ \\
\hline IL-2 & $\begin{array}{l}\text { Promotes clonal expansion and development of T and } \\
\text { B-lymphocytes. } \\
\text { Induces expression of adhesion molecules. } \\
\text { Enhances the function of NK cells. }\end{array}$ & IL-10 & $\begin{array}{l}\text { Inhibits synthesis of Th1 cytokines such as IFN- } \gamma \text { and IL- } 2 \text {. } \\
\text { Inhibits antigen-presenting cells. }\end{array}$ \\
\hline IL-15 & $\begin{array}{l}\text { Induces activation and cytotoxicity of NK cells. } \\
\text { Activates macrophages. } \\
\text { Promotes proliferation and survival of T and B-lymphocytes and } \\
\text { NK cells. }\end{array}$ & IL-8 & $\begin{array}{l}\text { Promotes neutrophils chemotaxis and degranulation. } \\
\text { Promotes tumour angiogenesis. }\end{array}$ \\
\hline IL-21 & $\begin{array}{l}\text { Regulates proliferation and differentiation of T cells, B cells, and } \\
\text { NK cells. } \\
\text { Potently regulates cellular-mediated immunity and directs } \\
\text { cytotoxic T lymphocytes and NK cell effector activity in the } \\
\text { clearance of tumours. }\end{array}$ & IL-13 & $\begin{array}{l}\text { Inhibits inflammatory cytokine production. } \\
\text { Induces immunoglobulin E secretion from B-lymphocytes. }\end{array}$ \\
\hline
\end{tabular}

IFN- $\gamma$ : Interferon gamma; IL: Interleukin; NK: Natural killer.
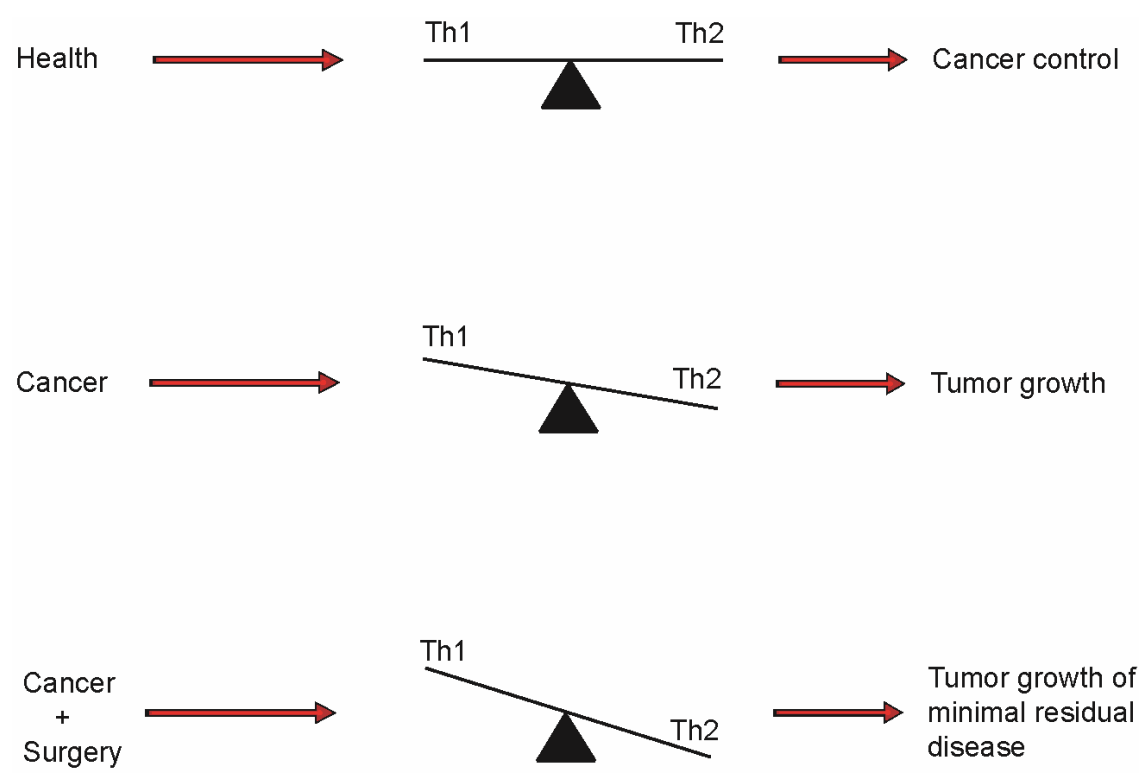

Figure 1. The Th1/Th2 balance in different heath states.

minimally affect the Th1/Th2 balance and perhaps be associated with better oncological outcomes [12].

The purpose of this review is to describe the perioperative variables that modify the Th1/Th2 balance. We will focus on its pattern during the perioperative period and the clinical and long-term implications of the misbalance in oncological surgical patients.

\section{The Th1/Th2 Balance during Cancer Surgery: The Th2 Dominant Immune State}

Few studies have clearly investigated the Th1/Th2 balance in the perioperative period of cancer surgery. The kinetics of Th1 and Th2 cytokines during the periopera- tive period remains difficult to study because they are not being measured at their maximum peak and most studies are done during in vitro conditions. Many studies have used immunoassays to measure the concentrations of Th1 and Th2 cytokines in serum/plasma, supernatants of stimulated peripheral blood mononuclear cells or, intracellularly $[13,14]$. Clinical studies indicate that the Th2 predominant state is the result of a decrease in Th1 cytokine production and enhancement of the Th2 response [14,15]. For instance, in patients with oesophageal cancer, Sato et al. [16] observed increased postsurgical serum concentrations of IL-8 and IL-10 that lasted 24 hours. These cytokine profiles were similar to those found in patients with squamous cell carcinoma of the larynx. Strey et al. 
[17] described the cytokine pattern among patients with hepatic metastases, primary intrahepatic cholangiocarcinoma, and primary hepatic carcinoma. The authors found higher concentrations of IL-10 among patients with extensive and prolonged surgery and among patients with delayed postoperative recovery [17]. An alternative hypothesis to the imbalance can be drawn from other studies in which the predominant Th2 state is the result of a decrease in Th1 response without an increase in the Th2 response [18,19].

Summarizing, the Th2 state associated with surgery is due to an increased of the Th2 cytokines with a relative decrease or no change in the Th1 cytokines.

\subsection{Extent of Surgical Trauma}

Catecholamines disrupt the Th1/Th2 balance towards a predominant Th2 state [20]. Thus, it is possible to speculate that the balance between Th1 and Th2 cytokines may change according to the magnitude of surgical invasiveness [21]. It is well known that in the context of cancer surgery, minimally invasive techniques have several advantages over open procedures including shorter hospital stay [22] and reduced infection rate [23]. Moreover, the smaller incisions of laparoscopic procedures are considered to produce less overall trauma and immunological disturbances at both cellular and humoral level compared with open surgery [14,24,25]. For instance, in patients undergoing colon cancer surgery, Tsamis et al. [26] documented higher serum concentrations of IFN- $\gamma$ in patients who underwent laparoscopic colectomy than in patients who underwent open surgery. This difference was sustained until the seventh postoperative day [26]. Open oesophageal cancer surgery has been associated with higher concentrations of IL-10 than laparoscopic resection [27].

Whether changes in the Th1/Th2 balance in response to surgical invasiveness correlate with long-term oncological prognosis is basically unknown. However, there are several studies that have tried to address the question of whether the degree of surgical invasiveness in associated to oncological outcomes. For instance, in patients with stage 1 non-small cell lung cancer the overall survival rate, only at 5 years, is better after open thoracotomy than video-assisted lobectomy; however, publication bias has been found in a recent metaanalysis [28]. Interestingly, the rate of systemic recurrences has been reported to be lower than after lobectomy [28]. Data from a large randomized controlled trial comparing open versus laparoscopic resection of colorectal cancers demonstrates that there are no differences in overall and disease-free survival [29]. A retrospective study in patients undergoing oesophageal cancer surgery failed to demonstrate an association between type of surgery (open versus laparoscopic) and overall survival [30]. Similar re- sults were found in gastric cancer surgery [23].

In summary, it seems that the higher the surgical trauma the more pronounced the alteration of Th1/Th2 balance, however; the impact of this imbalance on cancer recurrence and survival after oncological surgery are not clear and needs further study.

\subsection{Perioperative Blood Transfusion and Cancer Survival}

The concentrations of Th2 cytokines are increased in non-leukoreduced RBC units; hence during the administration of blood there is also infusion of those cytokines [31-33]. To complicate more this matter, the immune system of the blood recipient is able to trigger a significant Th2 response that is caused by the contact of the cellular and not cellular factors present in the transfused units to recipient's leukocytes. For instance, exposure of stored red blood cell (RBC) to whole blood triggers release of IL-10 [34], reduces lipopolysaccharide-induced release of TNF-a [35], and induces regulatory $\mathrm{T}$ cell (Treg) activation [36]. Interestingly, the enhanced released of IL-10 is not completely avoided when leukodepleted or autologous blood is used [37]. Moreover, it appears that the plasma non-cellular factors of the transfused units are responsible of a depressed Th1 response whereas the RBCs are involved in the enhanced Th2 response, thus turning the balance to predominant Th2 state.

Several retrospective studies have shown an association between blood transfusions and cancer recurrence [38-40]. Importantly, a meta-analysis demonstrated that blood transfusions in the perioperative period are associated with higher rates of cancer recurrence after colorectal cancer surgery [41]. However, it is unknown if the association between blood transfusions and cancer recurrence is due to a Th1/Th2 imbalance or other biological mechanisms.

\subsection{Opioids and Anaesthetics}

Opioids, the most commonly used analgesics in the perioperative period, also contribute to the Th1/Th2 imbalance by favouring Th2 over a Th1 response (Figure 2). The production of IL-4 and IL-5, increases [42] and that of IL-2 decreases after exposure of $\mathrm{T}$ lymphocytes and peripheral mononuclear cells to increasing concentrations of morphine [43]. Moreover, morphine decreases the expression of IL-2 by acting on the mu-receptor [44]. Humans receiving morphine have an increased mRNA expression of IL-4 in peripheral blood mononuclear cells, and in a positive feedback mechanism [45], IL-4 increases the expression of mu-receptors in the same cells [46]. Similarly, a clinical study demonstrated that the administration of fentanyl was associated with a predominant Th2 


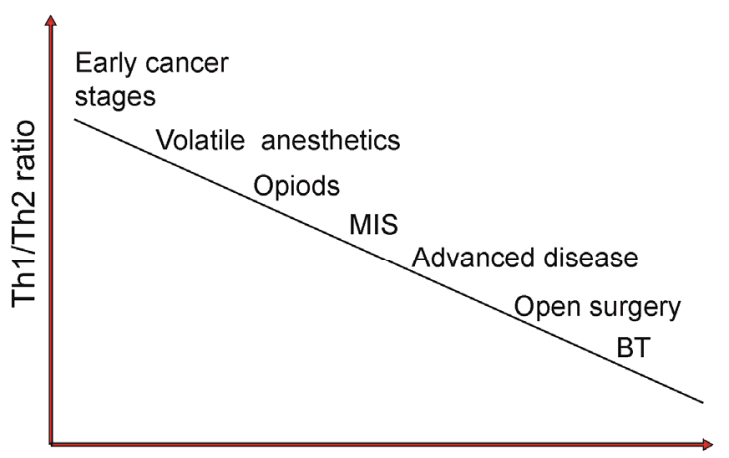

Perioperative period

Figure 2. Perioperative interventions that affect the Th1/ Th2 balance.

shift [47]. In regards to IL-10, it has been shown that the administration of high-dose morphine to intact animals provokes a sustained increase in IL-10 concentrations [48]. Interestingly, two clinical studies corroborated the findings in animals and indicate that the plasma concentrations of IL-10 are elevated after patient-controlled morphine analgesia and after sevofluraneopioid based anaesthesia $[49,50]$.

General anaesthetics also have important effects on the immune system (Figure 2) [51-53]. Propofol appears to improve or preserve the Th1/Th2 ratio [54,55] which is in distinct contrast to volatile anaesthetics and ketamine [56]. An in vitro study in which lymphocytes were obtained from patients exposed to the combination of fentanyl and propofol for 20 minutes and then stimulated with phytohemmagglutinin or lipopolysaccharide demonstrated a predominant Th1 response based on an IFN$\gamma / \mathrm{IL}-10$ ratio that was higher than before anaesthesia [52]. In healthy individuals, sevoflurane- $\mathrm{N}_{2} \mathrm{O}$-based general anaesthesia is associated with higher and lower plasmatic concentrations of IL-10 and IL-2, respectively, than is propofol-based general anaesthesia, although these differences seem to be transient and short-lived [57]. These findings are in contrast to those reported by Delogu et al., who did not find differences in the systemic concentrations of IL-10 between patients who underwent major surgery under total intravenous anaesthesia versus inhalational anaesthesia [58].

One of the means to reduce or even avoid volatile anaesthetics and decrease opioid consumption is using regional anaesthesia techniques. Thus, several investigators have hypothesized that these techniques would be associated with better immunological profiles and oncological outcomes [59,60]. Wada et al. showed, in an animal model, that the addition of spinal block to general anaesthesia decreased the number of liver metastasis induced by surgery. The authors speculated that this effect was related to the preservation of the Th1/Th2 balance after surgery [60]. Whether these findings translate in humans is completely unclear. The use of spinal anaesthesia was not associated with a lower or higher Th1/Th2 ratio compared with general anaesthesia in patients undergoing transurethral prostate resection for prostate hyperplasia. Although the authors did find a transient decrease in the plasma concentrations of IL-2 in the general anaesthesia group patients, these subjects had higher concentrations of the cytokine at baseline than those who had spinal anaesthesia [61]. Le Cras et al. found an increase in Th1 cells and decrease in Th2 cells in patients who underwent transurethral resection of the prostate with spinal anaesthesia compared with cancer patient with general anaesthesia, leading to an increase in the Th1/Th2 ratio. Thus, the ratio was higher in patients who received spinal anaesthesia compared with general anaesthesia [62]. Ahlers et al. reported similar findings in patients undergoing abdominal surgery. These authors demonstrated that the use of intraoperative epidural analgesia was associated with a higher Th1/Th2 ratio than when epidural analgesia was started postoperatively [63]. Remarkably, these findings are in striking contrast to those recently reported by $\mathrm{Vi}$ viano et al., who found that, in the majority of cancer patients undergoing thoracotomy, the use of epidural anaesthesia was associated with a lower Th1/Th2 ratio than that calculated for patients who received only remifentanil or remifentanil plus clonidine [64]. Finally, a clinical study demonstrated that the use of intraoperative high doses of fentanyl was associated with a reduction in IFN$\gamma$ concentrations; interestingly this phenomenon was partially reversed by the used of intraoperative epidural anaesthesia [63].

Whether or not the magnitude of the effect of opioids and anaesthetics on the Th1/Th2 balance is higher to that of cause by surgical stress in unknown. Several authors have hypothesized that the use of regional analgesia would not only ameliorate the stress response associated with surgery and the requirements of aesthetic and analgesic hence maintaining the Th1/Th2 balance but also it would have a significant impact on cancer recurrence [65]. Unfortunately, there is no clinical evidence from randomized controlled trials that indicate that the use of regional anaesthesia or analgesia technique is associated with better recurrence-free survival [66].

In summary, the predominant immunological response during and after surgery is Th2 type, and it is perhaps related to the magnitude of surgical stress and tissue damage and less likely to the type of anaesthesia technique used.

\section{Conclusion}

In conclusion, the perioperative period of oncological surgery represents a moment of immunological vulnerability characterized by a predominant Th2 response (immune suppression). The magnitude of the Th1/Th2 im- 
balance is most likely associated with the degree of surgical stress, the use of volatile anaesthetics, opioids and the administration of blood transfusions. Only retrospective studies have been conducted to assess the impact of regional anaesthesia on cancer recurrence. The results of those studies are controversial and given the lack of randomized control trials, we cannot conclude that a particular anaesthesia technique is associated with higher or lower rates of cancer recurrence. In contrast, strong evidence from a meta-analysis in colorectal patients indicates that blood transfusion are linked to poor oncological outcomes in this patients population.

\section{REFERENCES}

[1] J. E. Talmadge, K. M. Meyers, D. J. Prieur and J. R. Starkey, "Role of NK Cells in Tumour Growth and Metastasis in Beige Mice,” Nature, Vol. 284, No. 5757, 1980, pp. 622-624.

[2] S. Goto, M. Sato, R. Kaneko, M. Itoh, S. Sato and S. Takeuchi, "Analysis of Th1 and Th2 Cytokine Production by Peripheral Blood Mononuclear Cells as a Parameter of Immunological Dysfunction in Advanced Cancer Patients," Cancer Immunology, Immunotherapy, Vol. 48, No. 8, 1999, pp. 435-442.

[3] T. R. Mosmann and R. L. Coffman, "TH1 and TH2 Cells: Different Patterns of Lymphokine Secretion Lead to Different Functional Properties," Annual Review of Immunology, Vol. 7, No. 1, 1989, pp. 145-173. doi:10.1146/annurev.iy.07.040189.001045

[4] T. R. Malek and A. L. Bayer, "Tolerance, Not Immunity, Crucially Depends on IL-2,” Natural Review of Immunology, Vol. 4, No. 9, 2004, pp. 665-674.

[5] B. H. Li, S. B. Xu, F. Li, X. G. Zou, A. Saimaiti, D. Simayi, et al., "Stat6 Activity-Related Th2 Cytokine Profile and Tumor Growth Advantage of Human Colorectal Cancer Cells in Vitro and in Vivo," Cell Signal, Vol. 24, No. 3, 2012, pp. 718-725.

[6] R. Kim, M. Emi and K. Tanabe, “Cancer Immunosuppression and Autoimmune Disease: Beyond Immunosuppressive Networks for Tumour Immunity,” Immunology, Vol. 119, No. 2, 2006, pp. 254-264.

[7] R. Vallejo, E. D. Hord, S. A. Barna, J. Santiago-Palma and S. Ahmed, "Perioperative Immunosuppression in Cancer Patients," Journal of Environmental Pathology, Toxicology and Oncology: Official Organ of the International Society for Environmental Toxicology and Cancer, Vol. 22, No. 2, 2003, pp. 139-146.

[8] T. Udagawa, “Tumor Dormancy of Primary and Secondary Cancers,” Apmis, Vol. 116, No. 7-8, 2008, pp. 615628.

[9] V. W. Rusch, D. Hawes, P. A. Decker, S. E. Martin, A. Abati, R. J. Landreneau, et al., "Occult Metastases in Lymph Nodes Predict Survival in Resectable Non-Small-Cell Lung Cancer: Report of the ACOSOG Z0040 Trial,” Journal of Clinical Oncology, Vol. 29, No. 32, 2011, pp. 4313-4319.
[10] C. Y. Lu, Y. H. Uen, H. L. Tsai, S. C. Chuang, M. F. Hou, D. C. Wu, et al., "Molecular Detection of Persistent Postoperative Circulating Tumour Cells in Stages II and III Colon Cancer Patients via Multiple Blood Sampling: Prognostic Significance of Detection for Early Relapse,” British Journal of Cancer, Vol. 104, No. 7, 2011, pp. 11781184.

[11] C. M. Koebel, W. Vermi, J. B. Swann, N. Zerafa, S. J. Rodig, L. J. Old, et al., "Adaptive Immunity Maintains Occult Cancer in an Equilibrium State,” Nature, Vol. 450, No. 7171, 2007, pp. 903-907.

[12] J. P. Cata, V. Gottumukkala and D. I. Sessler, "How Regional Anesthesia Might Reduce Postoperative Cancer Recurrence,” European Journal of Pain Supplement, Vol. 5, No. S2, 2012, pp. 345-355.

[13] H. Tatsumi, H. Ura, S. Ikeda, K. Yamaguchi, T. Katsuramaki, Y. Asai, et al., "Surgical Influence on TH1/TH2 Balance and Monocyte Surface Antigen Expression and Its Relation to Infectious Complications," World Journal of Surgery, Vol. 27, No. 5, 2003, pp. 522-528.

[14] D. Decker, M. Schondorf, F. Bidlingmaier, A. Hirner and A. A. von Ruecker, "Surgical Stress Induces a Shift in the Type-1/Type-2 T-Helper Cell Balance, Suggesting DownRegulation of Cell-Mediated and Up-Regulation of Antibody-Mediated Immunity Commensurate to the Trauma," Surgery, Vol. 119, No. 3, 1996, pp. 316-325.

[15] M. Ishikawa, M. Nishioka, N. Hanaki, T. Miyauchi, Y. Kashiwagi, H. Ioki, et al., "Perioperative Immune Responses in Cancer Patients Undergoing Digestive Surgeries,” World Journal of Surgical Oncology, Vol. 7, No. 7, 2009, p. 7. doi:10.1186/1477-7819-7-7

[16] N. Sato, K. Koeda, Y. Kimura, K. Ikeda, M. Ogawa and K. Saito, et al., "Cytokine Profile of Serum and Bronchoalveolar Lavage Fluids Following Thoracic Esophageal Cancer Surgery,” European Surgical Research, Vol. 33, No. 4, 2001, pp. 279-284.

[17] C. W. Strey, R. M. Marquez-Pinilla, M. M. Markiewski, B. Siegmund, E. Oppermann, J. D. Lambris, et al., "Early Post-Operative Measurement of Cytokine Plasma Levels Combined with Pre-Operative Bilirubin Levels Identify High-Risk Patients after Liver Resection,” International Journal of Molecular Medicine, Vol. 27, No. 3, 2011, pp. 447-454.

[18] M. Zelic, D. Stimac, D. Mendrila, V. S. Tokmadzic, E. Fisic, M. Uravic, et al., "Influence of Preoperative Oral Feeding on Stress Response after Resection for Colon Cancer,” Hepato-Gastroenterology, Vol. 59, No. 117, 2012, pp. 1385-1389.

[19] R. Berguer, N. Bravo, M. Bowyer, C. Egan, T. Knolmaye and D. Ferrick, "Major Surgery Suppresses Maximal Production of Helper T-Cell Type 1 Cytokines without Potentiating the Release of Helper T-Cell Type 2 Cytokines," Archives of Surgery, Vol. 134, No. 5, 1999, pp. 540-544.

[20] H. W. Huang, J. L. Tang, X. H. Han, Y. P. Peng and Y. H. Qiu, "Lymphocyte-Derived Catecholamines Induce a Shift of Th1/Th2 Balance toward Th2 Polarization,” Neuroimmunomodulation, Vol. 20, No. 1, 2012, pp. 1-8.

[21] F. Greco, M. R. Hoda, N. Mohammed, C. Springer, K. Fischer and P. Fornara, "Laparoendoscopic Single-Site and 
Conventional Laparoscopic Radical Nephrectomy Result in Equivalent Surgical Trauma: Preliminary Results of a Single-Centre Retrospective Controlled Study,” European Urology, Vol. 61, No. 5, 2012, pp. 1048-1053.

[22] K. Galaal, A. Bryant, A. D. Fisher, M. Al-Khaduri, F. Kew and A. D. Lopes AD, "Laparoscopy versus Laparotomy for the Management of Early Stage Endometrial Cancer," Cochrane Database Systematic Review, Vol. 9, 2012, Article ID: CD006655.

[23] A. C. Gordon, K. Kojima, M. Inokuchi, K. Kato and K. Sugihara, "Long-Term Comparison of Laparoscopy-Assisted Distal Gastrectomy and Open Distal Gastrectomy in Advanced Gastric Cancer,” 2012.

[24] G. Di Vita, C. Sciume, S. Milano, R. Patti, G. L. Lauria, G. Di Bella, et al., "Th1-Like and Th2-Like Cytokines in Patients Undergoing Open versus Laparascopic Cholecystectomy,” Annali Italiani di Chirurgia, Vol. 72, No. 4, 2001, pp. 485-491.

[25] J. P. Desborough, "The Stress Response to Trauma and Surgery,” British Journal of Anaesthetic, Vol. 85, No. 1, 2000, pp. 109-117.

[26] D. Tsamis, G. Theodoropoulos, P. Stamopoulos, S. Siakavellas, T. Delistathi, N. V. Michalopoulos, et al., "Systemic Inflammatory Response after Laparoscopic and Conventional Colectomy for Cancer: A Matched Case-Control Study," Surgical Endoscopy, Vol. 26, No. 5, 2012, pp. 1436-1443.

[27] H. Tsujimoto, R. Takahata, S. Nomura, Y. Yaguchi, I. Kumano, Y. Matsumoto, et al., "Video-Assisted Thoracoscopic Surgery for Esophageal Cancer Attenuates Postoperative Systemic Responses and Pulmonary Complications,” Surgery, Vol. 151, No. 5, 2012, pp. 667-673.

[28] Z. Li, H. Liu and L. Li, "Video-Assisted Thoracoscopic Surgery versus Open Lobectomy for Stage I Lung Cancer: A Meta-Analysis of Long-Term Outcomes,” Experimental Therapeutic Medicine, Vol. 3, No. 5, 2012, pp. 886-892.

[29] B. L. Green, H. C. Marshall, F. Collinson, P. Quirke, P. Guillou, D. G. Jayne, et al., "Long-Term Follow-Up of the Medical Research Council CLASICC Trial of Conventional versus Laparoscopically Assisted Resection in Colorectal Cancer," British Journal of Surgery, Vol. 100, No. 1, 2013, pp. 75-82.

[30] H. Ichikawa, G. Miyata, S. Miyazaki, K. Onodera, T. Kamei, T. Hoshida, et al., "Esophagectomy Using a Thoracoscopic Approach with an Open Laparotomic or Hand-Assisted Laparoscopic Abdominal Stage for Esophageal Cancer: Analysis of Survival and Prognostic Factors in 315 Patients,” 2012.

[31] V. Weisbach, C. Wanke, J. Zingsem, R. Zimmermann and R. Eckstein, "Cytokine Generation in Whole Blood, Leukocyte-Depleted and Temporarily Warmed Red Blood Cell Concentrates," Vox Sanguinis, Vol. 76, No. 2, 1999, pp. 100-106.

[32] G. Stack, L. Baril, P. Napychank and E. L. Snyder, “Cytokine Generation in Stored, White Cell-Reduced, and Bacterially Contaminated Units of Red Cells," Transfusion, Vol. 35, No. 3, 1995, pp. 199-203.

[33] A. Shanwell, M. Kristiansson, M. Remberger and O. Ring- den, "Generation of Cytokines in Red Cell Concentrates during Storage Is Prevented by Prestorage White Cell Reduction,” Transfusion, Vol. 37, No. 7, 1997, pp. 678-684.

[34] O. Karam, M. Tucci, B. J. Toledano, N. Robitaille, J. Cousineau, L. Thibault, et al., "Length of Storage and in Vitro Immunomodulation Induced by Prestorage Leukoreduced Red Blood Cells,” Transfusion, Vol. 49, No. 11, 2009, pp. 2326-2334.

[35] M. B. Patel, K. G. Proctor and M. Majetschak, "Extracellular Ubiquitin Increases in Packed Red Blood Cell Units during Storage,” The Journal of Surgical Research, Vol. 135, No. 2, 2006, pp. 226-232.

[36] J. M. Baumgartner, C. C. Silliman, E. E. Moore, A. Banerjee and M. D. McCarter, "Stored Red Blood Cell Transfusion Induces Regulatory T Cells," Journal of the American College of Surgeons, Vol. 208, No. 1, 2009, pp. 110-119.

[37] A. E. Biedler, S. O. Schneider, U. Seyfert, H. Rensing, S. Grenner, M. Girndt, et al., "Impact of Alloantigens and Storage-Associated Factors on Stimulated Cytokine Response in An in Vitro Model of Blood Transfusion," Anesthesiology, Vol. 97, No. 5, 2002, pp. 1102-1109.

[38] T. S. Creasy, P. S. Veitch and P. R. Bell, “A Relationship Between Perioperative Blood Transfusion and Recurrence of Carcinoma of the Sigmoid Colon Following Potentially Curative Surgery," Annals of the Royal College of Surgeons of England, Vol. 69, No. 3, 1987, pp. 100-103.

[39] D. W. Moores, S. Piantadosi and M. F. McKneally, "Effect of Perioperative Blood Transfusion on Outcome in Patients with Surgically Resected Lung Cancer," The Annals of Thoracic Surgery, Vol. 47, No. 3, 1989, pp. 346-351.

[40] R. Chesi, A. Cazzola, G. Bacci, B. Borghi, A. Balladelli and G. Urso, "Effect of Perioperative Transfusions on Survival in Osteosarcoma Treated by Multimodal Therapy,” Cancer, Vol. 64, No. 8, 1989, pp. 1727-1737.

[41] A. Amato and M. Pescatori, "Perioperative Blood Transfusions for the Recurrence of Colorectal Cancer," Cochrane Database of Systematic Reviews, Vol. 1, 2006, Article ID: CD005033.

[42] K. M. Greeneltch, A. E. Kelly-Welch, Y. Shi and A. D. Keegan, "Chronic Morphine Treatment Promotes Specific Th2 Cytokine Production by Murine T Cells in Vitro via A Fas/Fas Ligand-Dependent Mechanism,” The Journal of Immunology, Vol. 175, No. 8, 2005, pp. 4999-5005.

[43] S. Roy, S. Balasubramanian, S. Sumandeep, R. Charboneau, J. Wang, D. Melnyk, et al., "Morphine Directs T Cells toward T(H2) Differentiation,” Surgery, Vol. 130, No. 2, 2001, pp. 304-309.

[44] C. Borner, B. Warnick, M. Smida, R. Hartig, J. A. Lindquist, B. Schraven, et al., "Mechanisms of Opioid-Mediated Inhibition of Human T Cell Receptor Signaling," The Journal of Immunology, Vol. 183, No. 2, 2009, pp. 882889.

[45] Q. Y. Zhang, M. Zhang and Y. Cao, "Exposure to Morphine Affects the Expression of Endocannabinoid Receptors and Immune Functions," Journal of Neuroimmunology, Vol. 247, No. 1-2, 2012, pp. 52-58. 
[46] J. Kraus, L. Lehmann, C. Borner and V. Hollt, "Epigenetic Mechanisms Involved in the Induction of the $\mathrm{Mu}$ Opioid Receptor Gene in Jurkat T Cells in Response to Interleukin-4,” Molecular Immunology, Vol. 48, No. 1-3, 2010, pp. 257-263.

[47] I. Z. Yardeni, B. Beilin, E. Mayburd, Y. Alcalay and H. Bessler, "Relationship between Fentanyl Dosage and Immune Function in the Postoperative Period," Journal of Opioid Management, Vol. 4, No. 1, 2008, pp. 7-33.

[48] R. Pacifici, S. di Carlo, A. Bacosi, S. Pichini and P. Zuccaro, "Pharmacokinetics and Cytokine Production in Heroin and Morphine-Treated Mice," International Journal of Immunopharmacology, Vol. 22, No. 8, 2000, pp. 603614.

[49] M. H. Kim and T. S. Hahm, "Plasma Levels of Interleukin-6 and Interleukin-10 Are Affected by Ketorolac as an Adjunct to Patient-Controlled Morphine after Abdominal Hysterectomy," The Clinical Journal of Pain, Vol. 17, No. 1, 2001, pp. 72-77.

[50] C. A. Deegan, D. Murray, P. Doran, D. C. Moriarty, D. I. Sessler, E. Mascha, et al., "Anesthetic Technique and the Cytokine and Matrix Metalloproteinase Response to Primary Breast Cancer Surgery," Regional Anesthesia and Pain Medicine, Vol. 35, No. 6, 2010, pp. 490-495. doi:10.1097/AAP.0b013e3181ef4d05

[51] C. E. Schneemilch, T. Hachenberg, S. Ansorge, A. Ittenson and U. Bank, "Effects of Different Anaesthetic Agents on Immune Cell Function in Vitro," European Journal of Anaesthesiology, Vol. 22, No. 8, 2005, pp. 616-623.

[52] J. M. Brand, C. Frohn, J. Luhm, H. Kirchner and P. Schmucker, "Early Alterations in the Number of Circulating Lymphocyte Subpopulations and Enhanced Proinflammatory Immune Response during Opioid-Based General Anesthesia,” Shock, Vol. 20, No. 3, 2003, pp. 213-217.

[53] J. M. Brand, H. Kirchner, C. Poppe and P. Schmucker, "The Effects of General Anesthesia on Human Peripheral Immune Cell Distribution and Cytokine Production," Clinical Immunology and Immunopathology, Vol. 83, No. 2, 1997, pp. 190-194.

[54] M. Salo, C. O. Pirttikangas and K. Pulkki, "Effects of Propofol Emulsion and Thiopentone on T Helper Cell Type-1/Type-2 Balance in Vitro," Anaesthesia, Vol. 52, No. 4, 1997, pp. 341-344.

[55] X. F. Ren, W. Z. Li, F. Y. Meng and C. F. Lin, "Differential Effects of Propofol and Isoflurane on the Activation of T-Helper Cells in Lung Cancer Patients,” Anaesthesia, Vol. 65, No. 5, 2010, pp. 478-482.

[56] N. Ohta, Y. Ohashi and Y. Fujino, "Ketamine Inhibits Maturation of Bone Marrow-Derived Dendritic Cells and
Priming of the Th1-Type Immune Response," Anesthesia \& Analgesia, Vol. 109, No. 3, 2009, pp. 793-800.

[57] C. E. Schneemilch, A. Ittenson, S. Ansorge, T. Hachenberg and U. Bank, "Effect of 2 Anesthetic Techniques on the Postoperative Proinflammatory and Anti-Inflammatory Cytokine Response and Cellular Immune Function to Minor Surgery,” Journal of Clinical Anesthesia, Vol. 17, No. 7, 2005, pp. 517-527.

[58] G. Delogu, A. Antonucci, M. Signore, M. Marandola, G. Tellan and F. Ippoliti, "Plasma Levels of Il-10 and Nitric Oxide under Two Different Anaesthesia Regimens,” European Journal of Anaesthesiology, Vol. 22, No. 6, 2005, pp. 462-466.

[59] S. Bar-Yosef, R. Melamed, G. G. Page, G. Shakhar, K. Shakhar and S. Ben-Eliyahu, "Attenuation of the Tumor-Promoting Effect of Surgery by Spinal Blockade in Rats,” Anesthesiology, Vol. 94, No. 6, 2001, pp. 10661073.

[60] H. Wada, S. Seki, T. Takahashi, N. Kawarabayashi, H. Higuchi, Y. Habu, et al., "Combined Spinal and General Anesthesia Attenuates Liver Metastasis by Preserving Th1/Th2 Cytokine Balance,” Anesthesiology, Vol. 106, No. 3, 2007, pp. 499-506.

[61] M. Zura, A. Kozmar, K. Sakic, B. Malenica and Z. Hrgovic, "Effect of Spinal and General Anesthesia on Serum Concentration of Pro-Inflammatory and Anti-Inflammatory Cytokines,” 2011.

[62] A. E. Le Cras, H. F. Galley and N. R. Webster, "Spinal but Not General Anesthesia Increases the Ratio of $\mathrm{T}$ Helper 1 to T Helper 2 Cell Subsets in Patients Undergoing Transurethral Resection of the Prostate," Anesthesia and Analgesia, Vol. 87, No. 6, 1998, pp. 1421-1425.

[63] O. Ahlers, I. Nachtigall, J. Lenze, A. Goldmann, E. Schulte, C. Hohne, et al., "Intraoperative Thoracic Epidural Anaesthesia Attenuates Stress-Induced Immunosuppression in Patients Undergoing Major Abdominal Surgery," British Journal of Anaesthesia, Vol. 101, No. 6, 2008, pp. 781-787.

[64] E. Viviano, M. Renius, J. C. Ruckert, A. Bloch, C. Meisel, A. Harbeck-Seu, et al., "Selective Neurogenic Blockade and Perioperative Immune Reactivity in Patients Undergoing Lung Resection,” Journal of International Medical Research, Vol. 40, No. 1, 2012, pp. 141-156.

[65] J. P. Cata, V. Gottumukkala and D. I. Sessler, "How Regional Analgesia Might Reduce Postoperative Cancer Recurrence,” European Journal of Pain Supplements, Vol. 5, No. 2, 2011, pp. 345-355.

[66] D. I. Sessler, "Does Regional Analgesia Reduce the Risk of Cancer Recurrence? A Hypothesis,” European Journal of Cancer Prevention, Vol. 17, No. 3, 2008, pp. 269-272. 